\title{
EIIDA
}

Revista Eletrônica de Estudos Integrados em Discurso e Argumentação

dx.doi.org/10.17648/eidea-16-2217

\section{O FUTURO CHEGOU HÁ POUCO TEMPO. DISPUTAS PELA ORDEM DEMOCRÁTICA ENTRE O DISCURSO PRESIDENCIAL E A IMPRENSA ESCRITA NO ÂMBITO DOS PANELAÇOS DE 2012 E 2013}

\author{
Julia de Diego ${ }^{\mathrm{i}}$
}

Resumo: Após a virada para o centro-direita na Argentina que significou a assunção de Mauricio Macri à presidência em 2015, perguntamo-nos sobre as condições de possibilidade sócio-discursiva que havia para a consolidação dessa força. Analisamos as definições de democracia presentes em dois tipos de discursos (político, da expresidente Cristina Fernández e jornalístico, de La Nación) emitidos após protestos de cidadãos chamados cacerolazos (2012-2013). Este último expressou uma enorme negatividade contra o governo Kirchner.

Palavras-chave: Democracia. Discurso político. Discurso periodístico. Kirchnerismo.

\begin{abstract}
After the turn to the centre-right in Argentina that meant the assumption of Mauricio Macri to the presidency in 2015, we asked ourselves about the conditions of socio-discursive possibility that there was for the consolidation of this force. We analyze the definitions of democracy present in two types of discourses (political, of the ex president Cristina Fernández, and journalistic, of La Nación) issued after citizen protests called cacerolazos (2012-2013). The latter expressed a massive negativity against the Kirchnerist government.
\end{abstract}

Keywords: Democracy. Politic discourse. Journalistic discourse. Kirchnerism.

\footnotetext{
' Doutora em Ciências Sociais pela Universidad Nacional de La Plata (UNLP) e membro do Instituto de Estudios Histórico-Sociales da Universidad Nacional del Centro de la Provincia de Buenos Aires (UNICEN). E-mail: juliadediego@yahoo.com.ar.
} 
EID\&A - Revista Eletrônica de Estudos Integrados em Discurso e Argumentação, Ilhéus, n. 16 esp. "Discurso e argumentação na política latino-americana, set.2018.

\section{Introdução}

A mudança de gestão política que propiciou a assunção de Mauricio Macri a presidência da Nação (Argentina) ${ }^{1}$ foi possibilitada por múltiplos e complexos processos que ainda não se podem definir completamente por causa de sua proximidade temporal. Como foi que a gestão política hegemônica do kirchnerismo esgotou a capacidade de representar e articular a ordem sociopolítica? E, por outro lado, qual espaço ocuparam (e que novos fenômenos foram nomeados) as definições da Proposta Republicana (PRO) que possibilitaram o triunfo de sua fórmula presidencial e a instauração de suas primeiras políticas? Especificamente, quais foram e como se estabeleceram as condições de possibilidade para que uma nova proposta política chegasse ao poder?

Se pensarmos retrospectivamente, o descontentamento social e o estabelecimento de novos espaços políticos e cidadãos de recusa da gestão que rapidamente se convergiram para a opção da aliança Cambiemos - já estavam dando variadas mostras de sua potência no espaço público. Em meio ao conflito entre o Governo nacional e o setor agropecuário em 2008 e o triunfo na célula da Alianza Cambiemos em novembro de 2015, os discursos opositores se expressaram massiva e publicamente em várias oportunidades. O ciclo de panelaços que compreendeu diversas manifestações ocorridas de 13 de setembro de 2012 a 8 de agosto de 2013 foi um exemplo disso. Foram mobilizações de setores médios que expressaram uma negatividade (política, econômica, cultural e emotiva) em relação ao Governo, a partir da exposição de uma heterogeneidade de demandas, não tão pontuais nem setoriais com havia sido as do Campo, mas muito críticas contra o governo de Cristina Fernández de Kirchner (CKF).

Estas palavras iniciais nos traçam um caminho teórico-analítico orientado, por um lado, a um estudo dos discursos políticos (e a politicidade dos discursos sociais), partindo da teoria política pós-fundacionalista, como abordagem que trará uma compreensão dos fenômenos da configuração pública de sentidos sobre a ordem social. No plano analítico, consideramos as definições sobre democracia como uma via de entrada relevante para ler as

\footnotetext{
${ }^{1} \mathrm{O}$ partido Propuesta Republicana (PRO) que levou Mauricio Macri à presidência surge depois da crise de 2001, junto com a Frente para la Victoria. Em sua curta história, seus dirigentes evitaram se enquadrar na denominação de direita, mas assim o fizeram seus diversos analistas (VOMMARO, 2016; RETAMOZO; SCHUTTENBERG, 2016), sendo endossada pelo ingresso do PRO na liga mundial dos partidos de direita, denominada União Democrata Internacional (CARELLI LYNCH, 2017).
} 
EID\&A - Revista Eletrônica de Estudos Integrados em Discurso e Argumentação, Ilhéus, n. 16 esp. "Discurso e argumentação na política latino-americana, set.2018.

formas em que os discursos políticos e jornalísticos disputaram horizontes de futuros diferentes. Podemos supor que a construção paulatina de um novo sentido da ordem social foi ancorada na cidadania à medida que tomava corpo na voz de diversos discursos públicos (e vice-versa) e que a disputa por definir o conceito de democracia se voltou a algumas concepções inteligíveis, legítimas e, nesse processo, finalmente capazes de ascender ao governo nacional. Em outras palavras, o triunfo da coligação Cambiemos e a derrota do kirchnerismo só podem ser compreendidos se analisar o modo em que se deu previamente a dimensão simbólica da contenta e como foi se configurando socialmente uma discursividade de centro-direita que a nova liderança articulou em seu discurso.

Diante de uma oposição política debilitada e sem capacidade de articulação política, grande parte dos jornais nacionais de capital privado protagonizaram esses questionamentos, cunhando suas próprias definições de democracia e fazendo diversas articulações com as expressões cidadãs.

Com esse interesse, analisaremos, por um lado, discursos presidenciais de CFK nos quais tenha se referido expressamente a democracia, pronunciados imediatamente depois de cada um dos panelaços. Veremos como sua concepção girou em torno da democracia como aprendizagem e práxis, como processo e construção, destacando a tradição democrática do peronismo e de um poder centrado em sua figura.

Como contrapartida, abordaremos os textos de opinião do jornal La Nación que analisaram essas alocuções oficiais. Observaremos ali um destaque da República como condição da ordem democrática. Prestaremos especial atenção à politicidade do discurso jornalístico, a partir de traços discursivos polifônicos, que se fundem com a voz de um outro-cidadão e exortam a oposição para o aparecimento de novas lideranças, mas que, finalmente, não se apropriam indevidamente da representação. Muitos desses traços haviam caracterizado sua gramática de produção discursiva entre 2003 e $2007^{2}$, a qual evidenciou forte continuidade e, portanto, sua coerência como ator político de relevância.

\footnotetext{
${ }^{2}$ Em De Diego (2017), vimos como La Nación analisou o primeiro kirchnerismo a partir de uma gramática político-ideológica refutativa, que se caracterizou pelos seguintes elementos: a) Polêmica, refutação e ressemantização; b) Questionamento das bases de poder; c) Questionamento das bases de decisão; d) Leitura dicotomizada do mapa político; e) Construção de uma Locutor próximo especialista-opositor; f) Construção de um laço de representação ideológicoopositor.
} 
EID\&A - Revista Eletrônica de Estudos Integrados em Discurso e Argumentação, Ilhéus, n. 16 esp. "Discurso e argumentação na política latino-americana, set.2018.

\section{A democracia e as disputas por seu sentido}

O questionamento sobre o caso argentino não é original, mas é o que está intrigando aqueles que estão formulando a teoria política contemporânea: como se constroem os sentidos da ordem social? De que forma se desenvolve em cada conjuntura o processo polêmico e público de definição dos significantes que nomeiam a ordem social hegemônica - e como esse cenário contribui para sua construção ou esgotamento? Quais identidades políticas configuram o ato de definir o conceito de democracia desejada? Quais atores políticos se propõem como capazes de impor suas visões como legitimas nominações definidoras dos sentidos da ordem social? A imprensa se tornou um desses atores?

Para pensar uma possível resposta, colocamos em diálogo o campo da comunicação social, os estudos do discurso e as contribuições que geraram a teoria politica pós-fundacionalista que versa sobre a concepção da democracia. Esta articulação nos permitirá a abordagem das definições conceituais como terreno de disputa e servirá de laboratório de observação dos processos de transformação política entre 2008 e 2016.

A tradição dos estudos em comunicação pós-estruturalistas reflete sobre a relação entre jornalismo e política a partir do ponto de vista da linguagem e da produção social de sentidos. Aqui, pensamos os discursos sociais por meio de uma perspectiva construtivista, valorizando os fenômenos de elaboração simbólica e discursiva como dimensão performativa do social (HEINICH; SCHAEFFER, 2004).

Incorporamos uma categoria de discurso que alude a todo conjunto significante considerado como lugar investido de sentido, sejam qual forem as materialidades (linguagem, corpo, imagem) (LACLAU, 2006). Não o concebemos como um reflexo mais ou menos certeiro de fatos extradiscursivos, mas que a construção do real se volta como possível na mesma rede da semiose social (VERÓN, 2004). Trata-se de uma "prática articulatória que constitui e organiza as relações sociais"; "atravessa a espessura material de instituições, rituais, práticas de diversas ordens, através das quais a formação discursiva se estrutura" (LACLAU; MOUFFE, 2004; p. 133 e 148). É partir disso que nomear a ordem social implica um ato performativo e de contundente carga política.

O discurso é material, dinâmico, histórico e social (VERÓN, 1993). Jamais pode repetir-se no tempo: é a dimensão significante de um objeto dinâmico 
EID\&A - Revista Eletrônica de Estudos Integrados em Discurso e Argumentação, Ilhéus, n. 16 esp. "Discurso e argumentação na política latino-americana, set.2018.

que, por um lado, se aborda a partir de determinadas condições de produção e, por outro, se lê desde outras condições de reconhecimento (múltiplas, complexas e diferentes no tempo).

As alocuções presidenciais e os textos jornalísticos de opinião são tipos de textos que, em um nível teórico, abordaremos como discurso político (VERÓN, 1987, 1998; BOURDIEU, 1984, 1984a) e discurso da informação ou jornalístico (VERÓN, 1984, 1987; ALSINA, 1989; BORRAT, 1989; CHARAUDEAU, 2003), respectivamente. Ambos podem compartilhar características discursivas polêmicas e retóricas, porém apresentam diferenças que podem ser pronunciadas ou enfraquecidas, de acordo com os contextos sóciopolíticos. No plano das condições de produção, a institucionalidade que os suporta responde a lógicas diferentes, uns são gestados em instituições públicas, outros em ambientes empresariais. Contudo, mais além das determinações institucionais, talvez um dos elementos que identifica os discursos políticos é a capacidade de construir coletivos de longo prazo (VERÓN, 1998), grupos sociais (BOURDIEU, 1984) ou agregados sociais (LATOUR, 2003), por meio da consolidação de laços representativos entre um líder e um grupo. Ainda que essas perspectivas não sejam iguais ${ }^{3}$, coincidem nesta instância em que a enunciação se torna política - em um sentido que implica uma práxis transformadora que busca performar socialmente um grupo - e não necessariamente quando se expressa a partir de uma instituição política. Trata-se de uma enunciação que assume uma tarefa de projeto e busca articular discursivamente tendências sociais, dando sentido a elas, e deriva em identidades políticas duradouras. Em suma, por politicidade de um discurso, compreendemos - mais além da institucionalidade e das características discursivas polêmicas e retóricas - a capacidade de uma locução pública de configurar (e representar) essas coletividades (que, por sua vez, delegam sua representação a um porta-voz) associadas a projetos de longo e médio prazo.

Se é possível pensar em uma pós-democracia (STAVRAKAKIS apud ACKERMAN, 2010) na qual as instituições e as eleições ainda funcionam, mas a participação popular fica reduzida no processo político e o jogo político tem as

\footnotetext{
${ }^{3}$ Neste sentido, resulta eloquente a análise que realiza Bermúdez (2014).
} 
EID\&A - Revista Eletrônica de Estudos Integrados em Discurso e Argumentação, Ilhéus, n. 16 esp. "Discurso e argumentação na política latino-americana, set.2018.

mídias como espaço central, a intervenção da imprensa se torna chave em momentos de grande conflitividade ${ }^{4}$.

Este enfoque supõe "que haja níveis de funcionamento dos processos políticos aos quais apenas podemos chegar por meio da análise do discurso" (VÉRON, 1987, p. 25), uma vez que permitem compreender melhor o mecanismo das instituições, sua natureza e suas transformações. Verón afirma que o ideológico (diferentemente da ideologia) refere-se ao nível de determinação dos discursos sociais que se torna visível apenas a partir da análise e que "remete aos vínculos que o sentido mantém com os mecanismos de base do funcionamento social" (VERÓN, 1995, p. 12). São parte das relações que estabelecem um discurso e suas condições (sociais) de produção (VERÓN, 2004).

Disso trata Laclau quando afirma que em nossas sociedades existe "uma proliferação de 'significantes flutuantes'“ e que a competência política se manifesta nas tentativas das forças políticas rivais de fixá-los parcialmente a configurações significantes particulares. Entendendo a democracia como sentido central nessa disputa, diz este autor que seu estudo é fundamental "para explicar a semântica política de nosso mundo político contemporâneo. Esta fixação parcial da relação entre significante e significado é o que se denomina 'hegemonia' nestes trabalhos" (LACLAU, 2004, p. 5). Em suma, a democracia será construída analiticamente como um ponto nodal (LACLAU; MOUFFE, 2004), ou seja, um significante cujo fluxo da discursividade se amarra, se detém e estabelece sentidos particulares.

Para compreender o interior, destacamos a bidimensionalidade da política que constitui o marco teórico pós-fundacional. Há uma ordem do político, que integra o que "constitui a polis", mas além do campo imediato da competência partidária e da ação governamental e da vida ordinária das instituições (ROSANVALLON, 2003): o terreno da política. Em outro sentido, falar do político remete a uma ordem incomensurável, a dimensão ontológica e constitutiva do social, que impera pela "ausência de um fundamento último", entendendo as ordens políticas como contingentes (MARCHART, 2009, p. 29).

\footnotetext{
${ }^{4}$ Verón (1998) sustenta que o discurso dos meios massivos de comunicação se diferencia do discurso político porque não constrói coletivos de longo prazo; no entanto, vê na imprensa escrita um possível âmbito de disputa pela representação política e a gestão de coletivos.
} 
EID\&A - Revista Eletrônica de Estudos Integrados em Discurso e Argumentação, Ilhéus, n. 16 esp. "Discurso e argumentação na política latino-americana, set.2018.

Se o fundamento de qualquer ordem social tem a ver com o político, dizemos que o democrático remete ao fundamento da ordem nas sociedades ocidentais que desenvolveram a democracia, não apenas como sistema de governo, mas sobretudo como forma de pensar o político; como uma ordem naturalizada a se defender. Lefort especifica suas características: nas democracias, o político remete a esse lugar vazio e inabitável, sobre o qual se erige uma ordem que, por sua natureza, é indeterminada, na medida em que a razão de ser dessa ordem se dá a partir da dissolução dos referentes da certeza, mediante o qual "os homens experimentam uma indeterminação última a respeito do fundamento da relação do um com o outro em todos os registros da vida social" (LEFORT, 1986, p. 50).

É assim que a democracia, como significante político, carrega no nome uma ordem do democrático, uma semântica da operação hegemônica; mas também é um ponto nodal que emerge no âmbito da democracia cotidiana, como terreno de disputa nas polêmicas públicas. Aí, como afirma Rosanvallon, a democracia (a partir do político) transforma a política em "um campo extremamente aberto" a partir das tensões e incertezas que a caracterizam. Nela se unem "o sonho do bem e a realidade do confuso", derrubando a crença de que existe um ideal distante em que haveria um acordo generalizado, e estabelecendo que "as divergências sobre sua definição remetem à ordem de mídias empregadas para realizá-la” (ROSANVALLON, 2003, p. 21).

Nessa linha, e retomando o início desta seção, a realização da democracia remete a uma série de elementos e ações para colocá-la em prática, entre as quais se encontra os discursos públicos. Estes são expressões que incidem no "duplo movimento de aparição e ocultação do modo de instituição da sociedade" (LEFORT, 1986, p. 39), de modo a potencializar ou mitigar a contingência da ordem democrática ou as contradições das diversas definições em disputa.

Em nossos termos, a conceptualização de democracia como significante torna-se uma ponte que conecta os mundos do democrático - aquela ontologia da indeterminação - e a democracia na qual se expressa a conflitividade das visões em disputa; a impossibilidade dos acordos em torno da definição de ordem, uma vez que as "condições para a vida em comum não estão definidas a priori, estabelecidas por uma tradição ou impostas por uma autoridade" (ROSANVALLON, 2003, p. 20). Em uma sociedade, como aponta 
EID\&A - Revista Eletrônica de Estudos Integrados em Discurso e Argumentação, Ilhéus, n. 16 esp. "Discurso e argumentação na política latino-americana, set.2018.

Lefort, "puramente social", dado que "nem o Estado, nem o povo, nem a nação figuram como realidades substanciais. Sua representação depende de um discurso político e de uma elaboração sociológica e histórica sempre ligada ao debate ideológico" (LEFORT, 1986, p. 49).

Por outro lado, na Argentina, democracia vem sendo um significante privilegiado para a compreensão das condições dinâmicas e de emergência de novas forças políticas. Vemos como os debates públicos em torno da definição do tipo de ordem social têm colocado as discussões nos anos 80, momento em que o alfonsismo apresentou uma instância "fundacional" que implicou uma ruptura com o "terror" anterior e uma promessa de uma nova ordem (ABOY CARLÉS, 2015). Esse contexto foi marcado pela tensão entre diversos sentidos, sendo democracia o significante organizador da discussão ideológico-política (REANO, 2011). A transformação estrutural da economia nos anos 90 pôde emergir acompanhada de um terreno discursivo em que a democracia deixou pouco a pouco de ser a condição para o crescimento, deixando esse papel para a estabilidade econômica (BARROS, 2002). O "imaginário de refundação" ressurge associado ao democrático na palavra do kirchinerismo, que no momento da crise de 2001 inscreve o neoliberalismo como contradestinatário discursivo privilegiado e reivindica a identidade nacional, a república democrática e a condição latinoamericana da Argentina (DAGATTI, 2016).

O caráter conflitivo da definição dos conceitos políticos não é interpretação inovadora - Voloshinov (1976, p. 36) já nos advertia que "o signo se converte em arena da luta de classes" -, mas nos orienta aqui a enfatizar as tensões inerentes à interpretação/construção política da realidade, uma vez que, como afirma Bourdieu (1984, p. 290), "o conhecimento do mundo social e, mais precisamente, das categorias que o possibilitam é o que está verdadeiramente em jogo na luta política", pois que conservar ou transformar o mundo social depende, em grande medida, de conservar ou transformar as categorias de percepção desse mundo.

Por meio de um olhar retórico-discursivo, Amossy estabelece que a polêmica pública - longe de ser uma mera e nociva deliberação - é parte constitutiva dos regimes democráticos; é o "paradigma de uma retórica do dissenso", que cumpre, não obstante, funções "importantes" no espaço público (AMOSSY, 2016, p. 25). A polêmica aparece então não como a impossibilidade de acordo, mas como um modo de gestão do conflito: é o 
EID\&A - Revista Eletrônica de Estudos Integrados em Discurso e Argumentação, Ilhéus, n. 16 esp. "Discurso e argumentação na política latino-americana, set.2018.

"assumir o controle das rupturas, frequentemente profundas, que dividem os cidadãos em uma democracia pluralista” (AMOSSY, 2016, p. 33).

Em suma, é no plano dos debates discursivos diários que se faz, desfaz e refaz a tentativa de nomear aquilo que não tem nome. É nesse jogo polêmico que se pode observar a luta para ancorar a definição mais apropriada e representativa da democracia, portadora de horizontes de futuro sobre as ordens sociais desejadas. Algumas dessas opções têm potencialmente "a capacidade de construir projetos" (ZEMELMAN, 2010) e as definições de amplos setores da cidadania que se constroem em diálogo com setores da oposição, na época do kirchnerismo, resultam um exemplo disso. O novo governo do PRO representou "uma potencialidade realizada em termos de determinadas alternativas de sentido", passou da "pura potencialidade, própria do primeiro momento [memória-utopia], que contém múltiplas possibilidades de sentido, à concretização de uma alternativa particular de sentido (ZEMELMAN, 2010, p. 359).

\section{A democracia representada: a análise das disputas em torno de seu sentido}

Conforme antecipamos, neste trabalho realizaremos um estudo sóciodiscursivo de alocuções presidenciais e jornalísticas que tenham como eixo o questionamento pelas definições de democracia. Este objetivo aponta para uma ordem de indagação do plano ôntico da política, que em termos discursivos podemos traduzir como um plano representado ${ }^{5}$, ou seja, o das definições conceituais.

A estratégia metodológica de trabalho contrastivo (ARNOUX, 2009) entre dois tipos discursivos nos permitirá colocar em diálogo alocuções de CFK com suas repercussões no La Nación - jornal que já vinha construindo um discurso opositor (DE DIEGO, 2017). Consideraremos suas particularidades discursivas (o qual, como analisamos em De Diego (2014), não permite uma equalização entre ambas discursividades), mas vamos rastrear operações de sentidos similares em torno das pretensões hegemônicas que postulam significados particulares como universais (LACLAU, MOUFFE, 2004).

\footnotetext{
${ }^{5}$ Retoma-se o modelo de análise de Montero (2012), que trabalha com a memória representada e incorporada no discurso de Néstor Kirchner. Em nossa linha de investigação, também consideramos central a análise de uma dimensão incorporada do pensamento democrático, encarnada em outras variáveis como as formas nas quais os diversos atores concebem a legitimidade, a representação, a dinâmica deliberada da política e as formas em que se esclarece os antagonismos, entre outros elementos. Ver esta proposta analítica em De Diego (2017a).
} 
EID\&A - Revista Eletrônica de Estudos Integrados em Discurso e Argumentação, Ilhéus, n. 16 esp. "Discurso e argumentação na política latino-americana, set.2018.

O trabalho será qualitativo, orientado por um paradigma interpretativo (VASILACHIS, 2009), cujo interesse está posto nos processos de produção de sentido. O método geral será o de uma análise discursiva, que articulará aportes da teoria política pós-estruturalista e aspectos dos estudos do discurso: a teoria da polifonia enunciativa (DUCROT, 1986), a análise de discurso polêmico (MONTERO, 2012; PLANTIN, 2012) e a análise do discurso político (VERÓN, 1987).

Nos discursos políticos, seguindo o modelo analítico que propõe Arnoux (2009), transcreveremos e "normalizaremos" os entornos do sintagma democracia, entendido como unidade léxica, de maneira que nos permita realizar comparações entre seus predicados.

Nos textos de opinião do La Nación, rastrearemos indícios de polifonia discursiva (DUCROT, 1986) que nos indiquem a posição do Locutor a respeito dos pontos de vista associados aos enunciadores presidencial e cidadão, podendo assim estabelecer a forma em que se posiciona diante das manifestações. Identificaremos, por sua vez, os modos como os textos jornalísticos incorporam as definições alheias: reformulação, seleção, ironia, oposição ou ressemantização. Por fim, analisaremos a dimensão projetiva na discursividade jornalística.

Construímos o corpus de análise tendo em conta uma hipótese políticohistórica a respeito de acontecimentos que constituíram marcos no processo de crescente visibilização massiva de um espaço social e político opositor ao kirchnerismo (que logo alimentaria a proposta do PRO, mas que não nasce deste partido). O PRO articulou demandas sociais e atores específicos, formando uma base social importante para a configuração de uma nova força política com potencialidade eleitoral. Centramo-nos no ciclo de protestos que se sucedeu entre 13 de setembro de 2012 e 8 de agosto de 2013, cujo marco condutor foi a negatividade, ou seja, a recusa a uma medida ou conjunto de medidas oficiais (GOLD, 2015). Segundo sustentam vários autores (GODFRID; ACOSTA, 2016; GÓMEZ, 2016), em 2012 ressurgem novos ciclos de "panelaços" (cuja origem alguns datam de 2008), um repertório de protesto que não é novo na Argentina, mas que apresenta suas particularidades: expressam o mal-estar de uma ampla gama de setores médios que mantém solidariedade com distintos grupos empresariais (GODFRID; ACOSTA, 2016). Esses atores se definiram melhor por diferentes produtores culturais com influência na 
EID\&A - Revista Eletrônica de Estudos Integrados em Discurso e Argumentação, Ilhéus, n. 16 esp. "Discurso e argumentação na política latino-americana, set.2018.

criação e reprodução de representações que por características essenciais (BRACCO, 2014).

Essas manifestações caracterizaram-se principalmente por reunir atores sociais urbanos que se declaravam abertamente contra uma diversidade de medidas do governo (sem levantar explicitamente bandeiras políticas de outro signo partidário); por contar com o apoio de grandes meios de comunicação (Clarín, La Nación e Todo Noticias) e por serem convocadas especialmente a partir das redes sociais. Essas mobilizações tiveram em comum, como sugere Gold, seu caráter de "explosão", cuja articulação não dependeu de uma dimensão identitária positiva (ainda assim há algumas demandas comuns), mas sim de uma negatividade: "a construção de identidades políticas a partir da recusa" (2015, p. 1983).

Foram quatro os panelaços que tomamos como referência para a seleção de discursos presidenciais e jornalísticos: 13/09/2013, 08/11/2012, $18 / 04 / 2013$ e 13/08/2013. Analisaremos quatro alocuções presidenciais que fizeram uma menção explícita à democracia ${ }^{6}$ e os textos de opinião do diário La Nación (editoriais, análises e colunas escritas por jornalistas estáveis do jornal), publicados dois dias após cada um dos atos oficiais ${ }^{7}$ mencionados.

\section{A Democracia no discurso de CFK: o "modelo" da práxis e da tradição}

No período em que observamos um processo de crescente visibilização de setores políticos e cidadãos em relação ao kirchnerismo, que se inicia em 2008, as concepções sobre democracia tomaram alguns matizes particulares no discurso de $\mathrm{CFK}^{8}$. No segmento 2012-2013, diferentemente de 2008, não se considera a oposição como um ator suficientemente unificado para atribuir-

\footnotetext{
${ }^{6}$ Entre as sete alocuções pronunciadas por Cristina Fernández após os panelaços, apenas em quatro delas encontramos tentativas de precisar conceitualmente a democracia: 1) Alocução posterior ao primeiro panelaço (14/09/2012); 2) Discursos pronunciados por Cristina Fernández no mesmo dia do segundo panelaço (08/11/2012); 3) Alocução presidencial na qual defendeu 0 "modelo" (09/11/2012); 4) Intervenção oficial no dia do terceiro panelaço (18/04/2013).

${ }^{7}$ Foram 22 textos. Seis deles foram publicados nos dias 15 e 16 de setembro de 2012 em relação ao discurso proferido por Cristina Fernández em San Juan no dia 14. Outros dez, nos dias 9, 10 e 11 de novembro, logo após as alocuções presidenciais dos dias 8 e 9. Os últimos seis faziam parte das edições de 19 e 20 de abril de 2013, após a intervenção da mandatária do dia 18.

${ }^{8}$ Existe uma ampla bibliografia sobre o discurso presidencial de Cristina Fernández. Kitzberger (2011) analisa o conflito entre o seu governo e os meio de comunicação como uma disputa contrahegemônica, enquanto que Vincent (2014) compreende como parte de um modelo de comunicação controlada. Resulta mais interessante a contribuição de Fernández (2016), que analisa as disputas pela representação no espaço público midiatizado, entre discursos políticos e discursos jornalísticos durante o "conflito do campo".
} 
EID\&A - Revista Eletrônica de Estudos Integrados em Discurso e Argumentação, Ilhéus, n. 16 esp. "Discurso e argumentação na política latino-americana, set.2018.

Ihe um tipo de democracia distinto (como a democracia corporativa, como definiu a mandatária em seu discurso de 17/06/2008). Naquele momento, CFK defendia uma democracia do diálogo, que no contexto dos panelaços transforma-se em democracia do modelo ou projeto. Da mesma forma, a pluralidade entre oposições eleitorais reorientou-se para a necessidade de incluir pluralidade dentro do próprio movimento justicialista. Já em 2015-2016, a referência à ordem democrática se desloca para o pedido de proteção e defesa dos direitos adquiridos; a dimensão afetiva da Pátria supera a democracia e exige um cuidado especial.

No momento dos panelaços, CFK não se pôs a confrontar de forma direta as manifestações - como havia feito durante o conflito com o agronegócio -, predominaram apenas referências elípticas e, na maioria das vezes, um espaço de vários dias depois de cada acontecimento. A democracia segue associada a regras que ordenam um exercício político como em 2008. Não aparece como um conceito teórico, mas como uma prática que se adquire em trânsito pelo jogo político, uma aprendizagem:

Sei o que é ser minoria, mas são as regras da democracia, quando alguém é minoria tem também a obrigação de estar sentado no banco, de estar sentado na Comissão, de estar discutindo, votar, e se os demais são maioria, essas são as regras da democracia. Eu disse, fui duramente atacada por ser minoria, internamente e também por acordos (18/04/2013).

Nesses discursos de CFK encontramos uma concepção de democracia mais associada a medidas políticas concretas que colocaram sua gestão como agente central no processo de democratização. A estratégia discursiva neste aspecto não foi a de atribuir aos "paneleiros" um tipo de democracia diferente, mas de fazer a menor referência possível a suas reivindicações e reforçar a defesa e os limites do "projeto" ou "modelo".

As referências explícitas à democracia já não se vinculam à vontade popular genérica (traço que havia sido notado em 2008 e que é retomado em 2015-2016), mas associadas aos adjetivos que qualificam o "projeto": nacional, popular e democrático (14/09/2012). A democracia aparece, nesse sentido, como síntese de mais moradia, mais educação e mais indústrias e como um projeto que deve "seguir avançando para todos os argentinos" (08/11/2012). A mandatária defendeu assim o "modelo" e associou a única possibilidade de mudança à construção de "um modelo alternativo", ainda inexistente, segundo sua perspectiva. 
EID\&A - Revista Eletrônica de Estudos Integrados em Discurso e Argumentação, Ilhéus, n. 16 esp. "Discurso e argumentação na política latino-americana, set.2018.

A tradição na qual se inscreveu CFK para definir este conceito contribuiu também para reforçar as fronteiras do modelo defendido. A democracia proposta foi cultivada na tradição desenvolvimentista do justicialismo desde 1945, que aposta em recuperar para o presente uma "sustentabilidade democrática de distintas ideias", que convivam dentro de um "grande movimento nacional" que incorpore diversas vertentes:

[...] sonho seguir reproduzindo esta incorporação, esta amplitude, esta sustentabilidade democrática de distintas ideias. Não temos que pensar todos exatamente a mesma coisa, não temos que viver todos a mesma história. Ao contrário, o que mais enriquece uma pessoa, o que mais enriquece um país, uma sociedade, é poder incluir e poder conviver e compartilhar ainda com aqueles que têm histórias diferentes, origens diferentes e ter assim um objetivo que deve ser comum a todos: a Pátria. (09/11/2012).

De acordo com este discurso, o "modelo" ou "projeto nacional, popular e democrático" faz parte de um processo que se viu conjugado em políticas de Governo como a "democratização de acesso à educação universitária" ou a democratização da justiça (o Poder Judicial "deve ser tão democrático quanto são o Poder Executivo e o Poder Legislativo") (18/04/2013). Se dá uma especial atenção (em dois dos discursos) a uma democratização específica, "a verdadeira reforma política" que remete, por um lado, às eleições primárias abertas, simultâneas, obrigatórias e, por outro, ao acesso aos meios de comunicação para realizar campanhas políticas.

Obviamente por isso os meio de comunicação, sobretudo os de grande ingerência, não gostam, mas creio que isto é muito saudável para a democracia, porque permite que todos façam conhecer seu pensamento aos cidadãos e permite uma melhor democracia. Porque, do contrário, é mentira que você escolhe. Se você pode somente escutar a um ou dois e não escuta o resto, é mentira que está escolhendo, não está escolhendo nada, simplesmente estão te impondo tal ou qual candidato. Por isso digo que a verdadeira reforma política foi introduzida quando, primeiro, colocamos, introduzimos a sociedade dentro dos partidos políticos para que, com as eleições simultâneas obrigatórias, o povo possa decidir os candidatos ou os pré-candidatos de cada partido e que não seja apenas uma questão burocrática ou de decisão interna do partido [...]. Realmente sabemos como isto é conduzido. Isto abriu aos partidos políticos e obrigou a todos e a cada um de nós a fazer nossos melhores esforços para conquistar o eleitorado e convencê-lo de que era a melhor opção para conduzir seus destinos, seja para um conselheiro, um intendente, um deputado, um senador, um governador. Eu me orgulho de tê-lo feito por que democratizamos a política. (09/11/2012).

Depois desta descrição, sintetizamos alguns dos traços que caracterizam a concepção de democracia presidencial: 
EID\&A - Revista Eletrônica de Estudos Integrados em Discurso e Argumentação, Ilhéus, n. 16 esp. "Discurso e argumentação na política latino-americana, set.2018.

- A democracia são regras que ordenam o jogo político (a respeito das minorias, eleições, liberdade de expressão, pertencimento partidário etc.);

- As regras são internalizadas no próprio exercício da militância: é uma tomada de consciência;

- A tradição peronista contribuiu para valorizar a democracia (por se opor à ditadura, por permitir a pluralidade interna);

- A democracia é um processo: pode haver graus de democracia que as políticas governamentais incrementarão;

- A democracia é um conceito histórico e suas principais características são contingentes (podem ser de outra maneira);

- A democracia é aumentar os direitos para o povo. Estes devem defender-se e proteger-se.

\section{As condições de possibilidade para uma nova ordem no La Nación}

Nas páginas do La Nación, a definição da ordem social tornou-se sem dúvida um terreno de disputa com a visão kirchnerista. Como todos os conceitos políticos, o de democracia tornou-se um significante vazio, cujas tentativas de preenchê-lo de sentido evidenciaram dimensões características do discurso político: a polêmica e a luta simbólica para outorgar um sentido próprio e diferente ao de um outro ao qual também se dá importância na mesma discursividade. Essa afirmação nos conduz a dois questionamentos:

1. Por que o discurso jornalístico assume esta função tão própria da enunciação política?

2. Se já é bem sabida a polissemia dos conceitos políticos e que é possível traduzir as diferenças políticas na luta para tentar tornar hegemônicas definições parciais como se fossem universais, qual particularidade assume o caso do La Nación, que nos permite observar uma dinâmica específica?

Estas questões exigem duas respostas entrelaçadas. Em primeiro lugar, diremos que o discurso da informação do La Nación assume um forte papel político - a partir do ponto de vista de suas características discursivas -, em um contexto de enfraquecimento das lideranças de oposição ao 
EID\&A - Revista Eletrônica de Estudos Integrados em Discurso e Argumentação, Ilhéus, n. 16 esp. "Discurso e argumentação na política latino-americana, set.2018.

kirchnerismo ${ }^{9}$. Essa posição foi potencializada a partir do que o periódico leu como uma ausência de lideranças nos protestos do panelaços; esse foi o argumento que fortaleceu a posição de um Locutor como representante de uma demanda social anti-kirchnerista que se construiu a partir de sua interpretação sobre as manifestações. Essa reflexão supôs o estabelecimento de um contrato de leitura (VERÓN, 1985) que continha um laço de representação ideológico-opositor. Este vinha sendo um elemento definidor da gramática político-ideológica de tipo refutativa (DE DIEGO, 2017) no La Nación desde o início do kirchnerismo ${ }^{10}$.

Em segundo lugar, propomos que a construção discursiva do La Nación assume traços particulares no modo como incorpora a voz de um outro: tomando como regra de produção discursiva os componentes refutativoressemantizador $^{11}$ e a lógica dicotomizante ${ }^{12}$ das análises políticas, observamos como a politicidade - que, veremos adiante, é uma politicidade particular - do discurso do La Nación o torna um ator que tenta definir uma ordem democrática desejada desde sua singularidade, sem intenção de deixar de mostrar que é apenas uma parte do mapa político. Sua definição traça uma fronteira frente ao que não é (e nunca será): o kirchnerismo, seus líderes, funcionários e "adeptos fanáticos". De acordo com as restrições de sua própria gramática, La Nación estabelece uma sutura de sentido, no interior dos limites toleráveis em relação àquele adversário. A operação busca ser

\footnotetext{
${ }^{9}$ Foram realizados alguns estudos sobre o discurso deste jornal durante o kirchnerismo que o colocam como opositor político (VINCENT, 2013), por meio de ideias opostas, como a de reconciliação (GONZALEZ; BORRELLI, 2009), no âmbito de uma identidade liberal-conservadora (SCHUTTENBERG; FONTANA, 2010).

${ }^{10}$ Componente da gramática que remete à relação que estabeleceu La Nación em seus espaços de opinião com a figura discursiva do receptor. Entre 2003 e 2007, configurou-se uma voz opositora ao kirchnerismo, que supôs um público leitor cúmplice desse posicionamento. O jornal ocupou um papel entre didático (VERÓN, 1987) e estratégico, a partir do qual manifestou conhecimento acerca das medidas políticas a serem tomadas e do caminho correto a seguir. Nesse contexto, La Nación não buscou disputar o laço representativo entre o poder político e a cidadania, mas apenas advertir sobre os direitos e as necessidades de uma cidadania democraticamente livre, consciente da necessidade da transformação política (DE DIEGO. 2017).

${ }^{11}$ Durante o primeiro kirchnerismo, La Nación ancorou suas definições no âmbito ideológico (VAN DIJK, 2008) contrário ao oficial, esclarecendo o limite entre o próprio e o alheio, sob uma modalidade discursiva de refutação e, em algumas ocasiões, ressemantização de conceitos políticos: recusou a perspectiva oficial, lhe outorgou um novo sentido, e a reinscreveu em um âmbito ideológico distinto (DE DIEGO, 2017).

${ }^{12}$ A gramática político-ideológica refutativa apresentou a realidade política em termos dicotômicos. Colocou o governo kirchnerista no espaço negativo e posicionou aqueles que questionavam o discurso oficial (empresários, banqueiros, nações poderosas, meios de comunicação concentrados) em um papel de vítimas. Esses buscavam consensos sem prepotência nem grosserias, pretendiam instituições fortes, integração internacional, regras de jogo estáveis; os outros eram revanchistas, sectários, prepotentes, tendiam a fazer negócios apenas com amigos, em busca de mesquinhos interesses partidários.
} 
EID\&A - Revista Eletrônica de Estudos Integrados em Discurso e Argumentação, Ilhéus, n. 16 esp. "Discurso e argumentação na política latino-americana, set.2018.

hegemônica como forma de estabelecer condições de possibilidade para a instauração dessa ordem desejada, mas não com o objetivo de se constituir em uma voz representativa da totalidade social. O diário fala a partir de um lugar, que busca estabelecer relações com esse mesmo lugar, o qual apoiará para que sejam os novos dirigentes.

O posicionamento político do La Nación demonstrado em um aumento de sua politicidade discursiva (discurso político refutativo-ressemantizador; laço representativo; construção de coletivos) foi uma constante durante todo o kirchnerismo. Em vários momentos, La Nación exortou a população para que construísse lideranças capazes de fazer frente ao oficialismo e, nesse pedido de ajuda, construiu-se a si próprio como um ator político de relevância, capaz de postular uma ordem democrática desejada. Isso nos conduz a afirmar que ele participa da polêmica não apenas como mero jornal crítico, mas que busca determinar que existem condições de possibilidade para que essa nova ordem triunfe.

Essa descrição está embasada na análise do três operações discursivas:

a) O apagamento das fronteiras de distinção entre a voz do Locutor e o ponto de vista ou enunciador (associado nos textos à “cidadania”), seguindo a categorização de Ducrot (1986).

b) Elementos do discurso polêmico: configuração de uma visão dicotomizante, manifestada em operações de refutaçãoressemantização.

c) Dimensão programática do enunciado, ressignificada nos quadros do discurso jornalístico: sem promessas, mas gerando condições de possibilidade para uma nova ordem política.

\section{a) O Locutor que fala em nome de seu grupo: a cidadania}

Observando que a palavra do La Nación assume - tanto por suas marcas discursivas, quanto por suas condições de produção e de reconhecimento um papel fortemente político, partimos do pressuposto de que seu dizer se associa ao que Bourdieu denominou como uma "palavra legítima"13

\footnotetext{
${ }^{13}$ Esclarecemos que Bourdieu não fala especificamente do discurso da imprensa, apenas que está pensando no discurso político, vinculado a espaços de enunciação da política tradicional (partidos, mandato presidencial etc.). Entretanto, consideramos que a "violência simbólica" que exerce o discurso do jornalismo massivo e privado (em qualquer de seus dispositivos) fortalece seu papel de portador de uma palavra legitimada socialmente como forma de compreender o mundo.
} 
EID\&A - Revista Eletrônica de Estudos Integrados em Discurso e Argumentação, Ilhéus, n. 16 esp. "Discurso e argumentação na política latino-americana, set.2018.

(BOURDIEU, 1984a), uma vez que contribui para a definição dos destinos de qualquer nação, a partir de críticas, recortes, enquadramentos, omissões etc.

A particularidade desse contexto e do diário La Nación é que essa politicidade explicita-se na propensão discursiva em conformar grupos, coletivos discursivos. Assume uma capacidade de nominação legítima, de emitir a voz massivamente autorizada para falar e, dessa forma, supõe-se um ato de delegação do grupo em direção ao porta-voz, para que nele resida o poder de falar em seu nome (BOURDIEU, 1984a). É assim que se consolida a partir do discurso jornalístico a suposição de que existe um laço de representação, fortalecido com o argumento de inexistência de lideranças opositoras dignas de conduzir esta necessidade de mudança política.

Bourdieu afirma que no discurso político "o mandatário deve de alguma maneira anular-se no grupo, entregar sua pessoa ao grupo, clamar e proclamar: 'Não existo a não ser pelo grupo'“ (1984a, p. 162). Não vemos uma operação tão extrema no La Nación, uma vez que a existência de um meio de comunicação e a autolegitimação de seu dizer depende de muitos outros fatores que o diferenciam de um mandato político (entre os quais se destaca o econômico: a mídia nunca deixa de ser uma empresa), mas sim analisamos as marcas discursivas que dão conta de um aumento de sua politicidade, na fusão - no total - da voz do Locutor jornalístico no grupo (a cidadania do panelaço).

De que forma, contudo, materializa-se esta operação nos discursos? Por meio da configuração de um sujeito falante na palavra jornalística, como a entidade puramente discursiva a qual denominaremos Locutor, seguindo a teoria polifônica da enunciação desenvolvida por Oswald Ducrot (1986). Nessa perspectiva, o autor de um enunciado não se expressa nunca de maneira direta, mas o faz por meio de uma encenação de pontos de vista, enunciadores, diante dos quais adota atitude diversas. O sentido do enunciado nasce assim da confrontação dessas diferentes vozes presentes nele e do posicionamento enunciativo do Locutor diante delas. Ducrot toma como unidade de análise os enunciados, mas nesta ocasião realizaremos o esforço interpretativo de reconhecer esses pontos de vista como conjuntos de enunciados, de maneira a poder caracterizá-los melhor em seu contexto discursivo.

No La Nación, observamos um forte valor argumentativo da fusão entre a voz do Locutor com um enunciador, o ponto de vista específico, a partir da 
EID\&A - Revista Eletrônica de Estudos Integrados em Discurso e Argumentação, Ilhéus, n. 16 esp. "Discurso e argumentação na política latino-americana, set.2018.

eliminação completa das marcas de diferenciação entre ambas as vozes. Este enunciador é um ponto de vista que em alguns momentos associa-se a atores específicos (os manifestantes, a cidadania), mas não tem necessariamente a ver com um sujeito; refere-se a uma voz ou posicionamento a respeito de algo: neste caso, a democracia.

O Locutor jornalístico incorporou a voz de um outro como sendo a sua, mas sem deixar de estabelecer sua própria impressão como voz especialista e representante. Em ocasiões de que vamos tratar, apagaram-se as marcas de diferenciação daquilo que o jornal nomeou como "cidadania", incorporando-a às próprias reivindicações dos principais colunistas. Do mesmo modo como fez durante o primeiro kirchnerismo, La Nación falou diretamente aos setores que defenderam perspectivas distintas da oficial.

$O$ que recurso que se estende à maioria dos $\operatorname{casos}^{14}$ foi o da construção de um Locutor que realizou a fusão de sua voz com o ponto de vista que encenou o da cidadania insatisfeita. Apenas em um dos casos o Locutor incluiu-se enunciativamente no coletivo de vítimas por meio do nós inclusivo (Grandona, 11/11/2012); o mais comum foi a dinâmica que descrevemos na sequência. Incluiremos aqui um fragmento que funciona como modelo de análise e é representativo de uma dinâmica discursiva recorrente no diário ${ }^{15}$ :

O povo fez ouvir seu cansaço. Cansaço diante da impunidade. Cansaço diante da insegurança. Cansaço diante da corrupção que abunda no poder. Cansaço diante da onipotência presidencial.

Com as mobilizações de quinta-feira a noite, em vários pontos do país, o povo reivindicou à Presidenta que ocupe o seu espaço e não o de todos.

E à oposição foi exigido que aprenda a ocupar o seu, que amadureça, que saiba representar aqueles que a convocam.

O povo fez ouvir um repertório de princípios e não apenas de necessidades econômicas, ainda que estas sejam ignoradas pelo poder tanto quanto esses princípios.

\footnotetext{
${ }^{14}$ Vale destacar que analisamos aqui nove textos em que foram explicitadas tentativas de disputar o sentido de democracia no plano representado. Contudo, a lógica de fusão entre a voz do Lucutor e o enunciador cidadão foi um invariante neste periódico (ver: Ed., 15/09/2012; Laborda, 16/09/2012; Sirvén, 16/09/2012; Morales Solá, 09/11/2012, Laborda, 09/11/2012, entre muitos outros).

${ }^{15}$ Outro exemplo: em Ed. (10/11/2012), o Locutor aparece também através do uso de um nós. Este preserva sua diferença a respeito do enunciador porque não está gramaticalmente na posição do sujeito, mas o coloca em um espaço de sofrimentos compartilhados: "Houve uma demanda [...] pelo fim das ilusões hegemônicas de nossos governantes". O locutor é quem "sintetiza" as mensagens, mas não é parte do coletivo (uso do impessoal) fortalecendo a transparência entre aquele que fala e em nome de quem o faz: "Todas essas mensagens poderiam ser sintetizadas em apenas uma, dirigida à presidenta da Nação: existem limites”. É no plano argumentativo que se aproxima ao enunciador-cidadão: "um cansaço em relação a uma concepção particular da política, que impera há nove anos, como um jogo irredutível de inimigos". A metaforização que alimenta uma argumentação pelas emoções é outro dos traços que potencializa a aproximação das vozes: "Canto à liberdade"; "Respirar liberdade”. Ver também: Ed. (20/04/2013).
} 
EID\&A - Revista Eletrônica de Estudos Integrados em Discurso e Argumentação, Ilhéus, n. 16 esp. "Discurso e argumentação na política latino-americana, set.2018.

O povo reivindicou instituições sólidas; desenvolvimento e liberdade de expressão. Disse não ao medo e sim à convivência. Não ao crime e sim à lei. Não à mentira e sim à verdade.

Pediu para ser governado e não submetido. Mais ainda: deixou bem claro que não se deixará submeter. (KOVADLOFF, 15/09/2012)

\section{Quadro 1}

\begin{tabular}{|c|c|c|}
\hline Locutor & Relação & Enunciadores \\
\hline $\begin{array}{l}\text { Posição inicial de exterioridade } \\
\text { a respeito do sujeito discursivo } \\
\text { "o povo": } \\
\text { - "O povo fez ouvir seu } \\
\text { cansaço"; } \\
\text { - "Pediu para ser governado e } \\
\text { não submetido"; } \\
\text { - "O povo reivindicou à } \\
\text { Presidenta". } \\
\text { O povo é uma terceira pessoa } \\
\text { (uma não-pessoa, nos temos de } \\
\text { Benveniste (1997)), da qual se } \\
\text { fala, mas a qual não se interpela } \\
\text { diretamente. Supõe-se que a } \\
\text { voz do jornal é transparente e } \\
\text { transmite o que esse "ele" }\end{array}$ & + & $\begin{array}{l}\text { E1: construção - ficcionalização - de um } \\
\text { ponto de vista associado ao povo } \\
\text { (cansaço; instituições sólidas; } \\
\text { desenvolvimento e liberdade de } \\
\text { expressão, convivência, lei, verdade). } \\
\text { - Sem sinais claros de diferenciação. } \\
\text { Pontos de maior identificação entre Le } \\
\text { E1: em enunciados que contêm } \\
\text { esclarecimentos: } \\
\text { "Cansaço diante da corrupção que } \\
\text { abunda no poder"; } \\
\text { "O povo fez ouvir um repertório de } \\
\text { princípios e não apenas de necessidades } \\
\text { econômicas, ainda que estas sejam } \\
\text { ignoradas pelo poder tanto quanto } \\
\text { esses princípios". }\end{array}$ \\
\hline $\begin{array}{l}\text { sente e demanda. } \\
\text { Há um Locutor jornalístico que } \\
\text { aparece por meio de marcas } \\
\text { textuais de polifonia: "O povo } \\
\text { fez ouvir um repertório de } \\
\text { princípios e não apenas de } \\
\text { necessidades econômicas, ainda } \\
\text { que estas sejam ignoradas pelo } \\
\text { poder tanto quanto esses } \\
\text { princípios". } \\
\text { A conjunção ainda é um } \\
\text { indicador polifônico que mostra }\end{array}$ & - & $\begin{array}{l}\text { E2: associado ao oficialismo. Condensa a } \\
\text { impunidade, a insegurança, a corrupção, } \\
\text { a onipotência presidencial, o medo, o } \\
\text { crime, a mentira e a submissão. } \\
\text { A negação marca em vários enunciados } \\
\text { esta encenação de um enunciador } \\
\text { oposto: } \\
\text { "Disse não ao medo e sim à convivência. } \\
\text { Não ao crime e sim à lei. Não à mentira e } \\
\text { sim à verdade. [...] Pediu para ser } \\
\text { governado e não submetido.". }\end{array}$ \\
\hline $\begin{array}{l}\text { que o Locutor jornalístico (o } \\
\text { ponto de vista que mostra } \\
\text { capacidade de síntese e de } \\
\text { representação, sem perder-se } \\
\text { totalmente no enunciador- } \\
\text { cidadão) é quem se encarrega } \\
\text { da enunciação. O Locutor é } \\
\text { quem denuncia ao acionar o } \\
\text { Governo. }\end{array}$ & - & $\begin{array}{l}\text { E3: associado à oposição. A fusão entre } \\
\text { L e E1 se reforça com a reivindicação: } \\
\text { "que amadureça, que saiba representar } \\
\text { aqueles que a convocam". }\end{array}$ \\
\hline
\end{tabular}

Fonte: Elaboração própria. 
EID\&A - Revista Eletrônica de Estudos Integrados em Discurso e Argumentação, Ilhéus, n. 16 esp. "Discurso e argumentação na política latino-americana, set.2018.

b) Uns e outros: lógica dicotomizante e operações de refutaçãoressemantização

A operação discursiva analisada anteriormente, na qual o Locutor jornalístico vincula-se estreitamente ao enunciador-cidadão, mas sem deixar de se situar em um lugar de representante deste, complementa-se com a disputa para outorgar-lhe um sentido ao conceito de democracia. Aqui, La Nación recria uma das características de sua gramática, a leitura dicotomizada do mapa político, e estabelece uma ordem democrática desejada, caracterizada por republicanismo ${ }^{16}$ marcado, que se institui frente a um presente da democracia simulada.

Veremos, então, como se põe em jogo um discurso polêmico do mais alto grau de recusa da palavra alheia, uma vez que se caracteriza pela refutação/ressemantização. Monteiro (2012) afirma que essa operação aparece quando o Locutor opõe-se a um discurso efetivo, cancelando o marco ou espaço discursivo em que esse discurso contrário se inscreve; a refutação implica, então, sempre a anulação do marco semântico de outro locutor. Segundo Plantin (2012), a refutação supõe destruição da voz do outro e pode ser acompanhada de uma contra-argumentação. É desse modo que, como vemos no La Nación, a refutação é acompanhada de uma retificação, orientada a ressemantizar ou ressignificar o discurso do outro, ao que se busca atribuir um novo sentido (MONTERO, 2012).

Na maior parte dos textos do La nación, o que se recusa não é um discurso efetivamente pronunciado, mas a ficcionalização de um outro na própria discursividade jornalística. A República (associada às liberdades individuais, ao respeito pela divisão de poderes, à competividade e à alternância) aparece como uma das ordens a proteger. A leitura é que durante o kirchnerismo reinou o medo, o monopólio do poder, o autoritarismo, e o curso da história mostra um "renascer", uma esperança de retorno dos valores republicanos. Surge, então, uma visão de democracia própria, por oposição: a descrição do não democrático gera a condição de possibilidade do que é sim democrático. Por questões de espaço não poderemos aprofundar nos elementos que caracterizam a refutação polêmica do La Nación, mas

\footnotetext{
${ }^{16}$ É eloquente nesse sentido o trabalho de Adamobsky (2017), no qual expressa que a República funcionou como significante privilegiado para os discursos de "direita" na época da campanha presidencial de 2015 e que estes rotularam o governo atual de "populista", como expressão de um modelo anti-republicano. Sustenta que a oposição (em termos gerais) diagnosticou que a República estava em perigo e o PRO - sobretudo após a morte do fiscal Alberto Nisman “conseguiu se converter em representante da salvação da República” (2017, p. 13).
} 
EID\&A - Revista Eletrônica de Estudos Integrados em Discurso e Argumentação, Ilhéus, n. 16 esp. "Discurso e argumentação na política latino-americana, set.2018.

interessa-nos esclarecer os modos em que se refuta um tipo de democracia, ressignificando-a em um novo modelo de ordem desejado. Vejamos os dois "modelos" de democracia que jornal opõe.

\section{Quadro 2}

\begin{tabular}{|c|c|}
\hline Democracia (ordem desejada) & $\begin{array}{l}\text { Anti-democracia (ordem a ser } \\
\text { transformada) }\end{array}$ \\
\hline $\begin{array}{l}\text { - Ordem democrática e republicana; } \\
\text { - Sistema de alternâncias; } \\
\text { - É necessária a organização da oposição } \\
\text { em uma efetiva força política capaz de } \\
\text { ganhar eleições; } \\
\text { - A democracia não se identifica com as } \\
\text { eleições, é um sistema de valores, uma } \\
\text { forma de vida em comum; } \\
\text { - Base da democracia mínima (retoma } \\
\text { Huntington). Três condições para as } \\
\text { eleições: } \\
\text { a) recontagem honesta dos votos; } \\
\text { b) que o candidato do governo não } \\
\text { disponha a seu favor dos recursos do } \\
\text { Estado; } \\
\text { c) que aquele que se candidate não seja } \\
\text { mais uma vez o próprio chefe de Estado } \\
\text { (Grondona, 11/11/2012). }\end{array}$ & $\begin{array}{l}\text { - Deformação: democracia muito pouco } \\
\text { competitiva (aquele que manda está } \\
\text { separado daquele que deveria limitá-lo } \\
\text { por } 37 \text { pontos); } \\
\text { - Monopólio do poder (Pagni, 15/09/2012); } \\
\text { - Caudilhismo vitalício; } \\
\text { - Tentação a nova reeleição: visão } \\
\text { reducionista da democracia (Grandona, } \\
\text { 11/11/2012); } \\
\text { - Quase desaparecimento da República } \\
\text { (Kovafloff, 19/04/2013); } \\
\text { Aniquilamento da independência dos } \\
\text { poderes da República; } \\
\text { - Grau precário de auto-suficiencia, } \\
\text { desprezo visceral pela opinião alheia e } \\
\text { recusa às contribuições críticas e } \\
\text { enriquecedoras de outros setores; } \\
\text { - Estilo de gestão, no inverso do exercício } \\
\text { democrático: despreza e rejeita o parecer } \\
\text { alheio e o utiliza como arma para } \\
\text { acrescentar seus enfrentamentos } \\
\text { impondo sua vontade (Ed, 19/04/2013). }\end{array}$ \\
\hline
\end{tabular}

Fonte: Elaboração própria.

c) Dimensão programática: as condições de possibilidade para uma nova ordem

Outro dos elementos que fortalecem a politicidade do discurso do La Nación é o que incorpora a dimensão de futuro em sua proposta acerca da democracia. Esta se posiciona como um pivô entre a atual situação que se define como problemática e um futuro com valores necessários bem definidos, mas com liderança incerta.

Verón afirma que entre os elementos que definem o discurso político encontram-se os componentes que funcionam como articuladores entre o enunciado e a enunciação, uma vez que definem as modalidades por meio das quais o enunciador (o Locutor, na terminologia de Ducrot) constrói sua rede 
EID\&A - Revista Eletrônica de Estudos Integrados em Discurso e Argumentação, Ilhéus, n. 16 esp. "Discurso e argumentação na política latino-americana, set.2018.

de relações com as entidades do imaginário (os coletivos: de identificação, entidades amplas, meta-coletivos singulares, formas nominalizadas e formas nominais). Entre esses componentes, menciona o programático, que é o momento em que "o homem político promete, anuncia, se compromete", é “da ordem do poder fazer" (VERÓN, 1987, p. 22).

O componente programático do La Nación mostra os limites da politicade do discurso da informação. Não há compromissos concretos, nem promessas, nem pretensão de representação política no Estado, mas contribui para gerar condições de possibilidade para uma mudança política. Preve-se uma mudança, para a qual reivindicam-se lideranças. Este é um traço recorrente ${ }^{17}$, mas tomamos um dos textos como exemplo:

Se algo novo nasceu na quinta-feira passada não é, por enquanto, similar aos sistemas frustrados dos últimos oitenta anos, porque o que os caracterizou foi o empenho de uma minoria para monopolizar nossa vida política. [...] Mas basta esta ampla convocação para fundar um sistema destinado a perdurar? [...] É como se já contássemos com os ingredientes básicos para construir o sistema de alternâncias que é a democracia. [...] Duas são as condições que ainda teriam que se estabelecer entre nós, diríamos, para assegurar a fundação de um sistema democrático e republicano. Uma, que as forças da oposição democrática se unissem para competir com o Governo [...]. A outra, que o próprio Governo começasse a renunciar diante do inevitável: a impossibilidade constitucional de Cristina pretender um terceiro mandato consecutivo em 2015. (GRANDONA, $11 / 11 / 2012)$

\section{Palavras finais}

As definições que reconstruímos a partir da análise dos discursos presidenciais de CFK foram um híbrido entre os particularismos vinculados aos contextos imediatos de sua enunciação e algumas dimensões transversais que contribuem para pensar a ordem social defendida por esta discursividade.

Entre 2012 e 2013, a disputa pela ordem supunha não classificar nem nomear um adversário, mas reforçar as características democratizadoras do modelo ou projeto. Foi ao mesmo tempo uma amostra de traços que se estabeleceram como invariantes, referidos à democracia como regra que ordena o jogo político (respeito às minorias, eleições, liberdade de expressão, pertencimento partidário etc.); são todas questões que se aprendem no próprio exercício da militância, a partir de uma tomada de consciência democrática; a tradição peronista contribuiu para valorizar a democracia (por

\footnotetext{
${ }^{17}$ Ver, por exemplo, Kovadloff, 19/04/2013; Dernández Díaz, 19/04/2013; Pagni, 15/09/2012.
} 
EID\&A - Revista Eletrônica de Estudos Integrados em Discurso e Argumentação, Ilhéus, n. 16 esp. "Discurso e argumentação na política latino-americana, set.2018.

se opor à ditadura, por permitir a pluralidade interna); a democracia é um processo; a democracia é um conceito histórico e suas principais características são contingentes; a democracia é aumentar os direitos para o povo, que devem defender-se e proteger-se.

Neste período, nos textos do La Nación que testaram sua própria definição de democracia, não retomaram expressões dos discursos para reformulá-las, apenas ficcionalizaram um outro, a partir de argumentações baseadas em sofrimentos compartilhados com o enunciador-cidadão. $O$ acento no "modelo" e na sua continuidade como processo democratizador teve seu correlato no La Nación ao lado das críticas de monopólio de poder, de tenção de nova reeleição, de caudilhismo vitalício, que desemboca na deformação de uma democracia pouco competitiva. A questão das regras democráticas também supuseram uma tensão entre ambas as discursividades: enquanto que nas alocuções políticas a democracia apareceu associada a uma práxis política própria da militância que produz a incorporação das regras no plano da experiência, no La Nación, essas normativas foram claramente republicanas, nos preexistem e são valores inacessíveis; não há como incorporá-las, apenas cumpri-las. Esta última percepção outorga uma imanência à ordem republicana que é também tensionada com a historicidade do conceito que aparece em vários discursos de CFK. A ideia de que o pluralismo deve ser fomentado no interior do movimento justicialista, somado ao estilo decisionista que a própria mandatária reconhecerá no mandato seguinte (como por exemplo na alocução de 29/10/2015), são também elementos muito questionados pelo La Nación. Eles supõem um quase desaparecimento da República devido a um grau precário de auto-suficiência, visceral despreso pela opinião alheia e recusa às contribuições críticas e enriquecedoras de outros setores.

La Nación não buscou disputar o laço de representatividade entre o poder político e a cidadania. Em consonância com o tipo de contrato construído - jornal opositor / leitor opositor -, não pretendia conceber uma visão holística da cidadania, mas apenas advertir a presença de distintos setores. O diário apelou para uma cidadania atenta a seus direitos e suas necessidades: um setor democraticamente livre, consciente da necessidade de transformação política e inclinada a concordar com as propostas dos colunistas políticos do La Nación. 
EID\&A - Revista Eletrônica de Estudos Integrados em Discurso e Argumentação, Ilhéus, n. 16 esp. "Discurso e argumentação na política latino-americana, set.2018.

O jornal contribuiu com seu discurso para criar condições de possibilidade para o surgimento de uma nova ordem sócio-política. Não falamos de uma postura que procurou rupturas ou reformas estruturais, mas apenas uma mudança de gestão política. A dimensão programática, nesse sentido, foi chave: o futuro promissor aparece associado ao aparecimento de novas lideranças que canalizem a nova esperança democrático-republicana.

O componente da gramática que se caracterizou entre 2003 e 2007 como a construção de um laço opositor seguiu operando como regra produtora de discursos do La Nación. No entanto, diante do contexto político que implicou a visibilização de um massivo setor social opositor, observamos uma nuance interessante: a identificação com este setor social que aparece no diário como vazio de liderança, enquanto que no início do kirchnerismo não se apresentava uma articulação visível com um setor social, mas apenas com uma ideia ou uma intenção política.

A aproximação entre as vozes jornalística e cidadã - sem chegar a se fundir completamente, o que teria levado a perder o papel de Locutor jornalístico - se fortaleceu com uma dinâmica complementar: a construção de um outro, localizado do lado oposto da ordem republicana e que atenta contra ela.

Se há algo que compartilham as discursividades presidenciais e do La Nación é a leitura dicotomizante da realidade política. Nesses momentos de crise, na tentativa de definir a democracia, cada discursividade o faz como uma parte que poderia se expressar como um todo tentando uma operação hegemônica, mas não se trata disso. Trata-se de uma operação política truncada pela própria natureza dos discursos dicotomizantes (determinados por lógicas refutativas-ressemantizadoras), uma vez que uma parte do conjunto social sempre ficará fora do laço de representação. Isto por se tratar de um outro, um diferente que atenta contra os interesses do coletivo que se vê representado.

\section{Fontes}

ACKERMAN, Sebastián. Entrevista a Yannis Stavrakakis: Nadie puede enamorarse del mercado. 6 de septiembre, 2010. Disponível em: https://www.pagina12.com.ar/diario/suplementos/espectaculos/17-19191-2010-0906.html. Acesso em: 29 mar.2017. 
EID\&A - Revista Eletrônica de Estudos Integrados em Discurso e Argumentação, Ilhéus, n. 16 esp. "Discurso e argumentação na política latino-americana, set.2018.

CARELLI LYNCH, Guido. El PRO ingresa a la liga mundial de los partidos de derecha. Clarín, 28 de enero. 2017. Disponível em: http://www.clarin.com/politica/pro-ingresaliga-mundial-partidos-derecha_O_HkVrpo5Px.html. Acesso em: 27 mar. 2017.

EDITORIAL. "Cacerolas que convocan a la unión de los argentinos". La Nación, Buenos Aires, 15 set. 2012.

. La marcha: un freno a la soberbia y al autoritarismo. La Nación, Buenos Aires, 10 nov. 2012.

. Un gobierno que se niega a escuchar y debatir. La Nación, Buenos Aires, 19 abr. 2013.

. Los mensajes del 18-A. La Nación, Buenos Aires, 20 abr. 2013.

FERNÁNDEZ DE KIRCHNER, Cristina. Alocución en la conmemoración del $53^{\circ}$ aniversario del bombardeo a la Plaza de Mayo y anuncio de envio del proyecto de retenciones al Congreso. Cadena nacional, 17 jun. 2008.

. Alocución durante el acto por la ampliación de la firma textil Lacoste. San Juan, 14 set. 2012.

. Alocución en el recibimiento a los participantes de la IV reunión binacional de ministros de Argentina-Chile. Olivos, 8 nov. 2012. nov. 2012.

. Alocución en la inauguración del Centro Cultural "Amigo Néstor”. Ezeiza, 8

. Alocución en la reunión con intendentes bonaerenses. Casa de Gobierno, 9 nov. 2012.

. Alocución en la inauguración de la Planta de Laminados Industriales S.A. Villa Constitución, Santa Fe, 12 nov. 2012.

. Alocución en la entrega de libros, a través del programa "Más libros en las aulas" en videoconferencia con Tucumán, General Belgrano y Areco. Casa de Gobierno, 18 abr. 2013.

. Alocución en el lanzamiento del programa Agrovalor. Tecnópolis, 14 ago. 2013.

. Alocución presidencial en el acto de adjudicación de obras represas "Néstor Kirchner-Jorge Cepernic", en teleconferencia con las localidades de Mercedes y Bahía Blanca, 21 ago. 2013.

- Alocución en el acto de inauguración del Archivo Histórico de RTA y lanzamiento del proyecto 'Bosques Nativos y Comunidad'. Palabras a los militantes. Casa Rosada, 29 out. 2015.

FERNÁNDEZ DÍAZ, Jorge. Se necesita un Alfonsín. La Nación, 19 abr. 2012. 
EID\&A - Revista Eletrônica de Estudos Integrados em Discurso e Argumentação, Ilhéus, n. 16 esp. "Discurso e argumentação na política latino-americana, set.2018.

GRONDONA, Mariano. El 8-N, ¿surgió un nuevo sistema político?. La Nación, 11 nov. 2012.

KOVADLOFF, Santiago. Lo que la gente puso en marcha. La Nación, Buenos Aires, 15 set. 2012.

. La República, a punto de convertirse en la nueva desaparecida. La Nación, Buenos Aires, 19 abr. 2013.

LABORDA, Fernando. Cristina, la gente y la trampa del fundamentalismo. La Nación, Buenos Aires, 16 set. 2012.

2012.

. En defensa de un valor supremo: la libertad. La Nación, Buenos Aires, 9 nov.

MORALES SOLÁ, Al borde de una crisis política y social, La Nación, Buenos Aires, 11 nov. 2012.

. Ella, en el centro del enojo. La Nación, Buenos Aires, 9 nov. 2012.

PAGNI, Carlos. Efectos de una democracia poco competitiva. La Nación, Buenos Aires, 15 set. 2012.

SIRVÉN, Pablo. Hay una cacerola en tu cabeza. La Nación, Buenos Aires, 16 set. 2012.

\section{Referências}

ABOY CARLÉS, Gerardo. "Persistencias de la fundación". In: LAZZERETTI, A. R.; SUÁREZ, F. M. (Coord.). Socialismo \& democracia. Mar del Plata: Eudem, 2015. p. 117142.

ADAMOVSKY, Ezequiel . El cambio y la impostura. Buenos Aires: Planeta, 2017.

ACOSTA, María de la Paz; GODFRID, Julieta. La influencia de las redes sociales en los 'cacerolazos' 2012-2013.", IV Encuentro internacional de teoría y práctica política en América Latina. UNMDP, Mar del Plata, 9 a 11 de março, 2016.

AMOSSY, Ruth. Por una retórica del dissensus: las funciones de la polémica. In: MONTERO, A. S. (Comp.). El análisis del discurso polémico. Buenos Aires: Prometeo, 2016.

ARNOUX, Elvira Narvaja de. Análisis del Discurso. Modos de abordar materiales de archivo. Buenos Aires: Santiago Arcos, 2009.

BARROS, Sebastián. Orden, democracia y estabilidad. Discurso y política en la Argentina entre 1976 y 1991. Tese (Doutorado). Universidad de Essex, 2002. 
EID\&A - Revista Eletrônica de Estudos Integrados em Discurso e Argumentação, Ilhéus, n. 16 esp. "Discurso e argumentação na política latino-americana, set.2018.

BENVENISTE, Émile. De la subjetividad en el lenguaje. In: . Problemas de lingüística general I. Siglo XXI, México, 1997.

BERMÚDEZ, Nicolás. Los modos de decir en la política. Una intervención al análisis del discurso. Revista Mexicana de Ciencias Políticas y Sociales. Año LIX, n. 221, p.99-120, 2014.

BORRAT, Héctor. El periódico, actor político. Barcelona: Gustavo Gili, 1989.

BOURDIEU, Pierre. Espacio social y génesis de las clases. In: . Sociología y cultura, México: Grijalbo, 1984 [1990]. p. 281-309.

. La delegación y el fetichismo político. In: . Cosas Dichas, Barcelona: Gedisa, 1996 [1984a]. p.158-172.

BRACCO, Olga. De progresistas y reaccionarios: Representaciones mediáticas sobre la clase media en la Argentina contemporánea. Trabalho de Conclusão de Curso. Universidad Nacional de La Plata. Facultad de Humanidades y Ciencias de la Educación, 2014. Disponível em: http://www.memoria.fahce.unlp.edu.ar/tesis/te.972/te.972.pdf

CHARAUDEAU, Patrick. El discurso de la información. La construcción del espejo social. Barcelona: Gedisa, 2003.

DAGATTI, Mariano. El anacronismo democrático. Militancia y democracia en las memorias generacionales del primer kirchnerismo. Confines, año 12, n. 22, p.37-78, enero-mayo, 2016,.

DE DIEGO, Julia. ¿Discurso político o politicidad de los discursos? Una propuesta para pensar la relación entre kirchnerismo y prensa. In: GINDIN, I. L. (Coord.). Kirchnerismo, mediatización e identidades políticas. Reflexiones en torno a la política, el periodismo y el discurso (2003-2008). Rosario: Cuaderno de Trabajo del CIM-UNR, 2014. p.17-36.

. La política mirada de frente. Gramáticas y posicionamiento de la prensa escrita durante el primer kirchnerismo. Buenos Aires: Eudeba. 2017.

. La democracia del cambio. Disputas de sentido en torno al orden social en Argentina (2008-2016). XII Jornadas de Sociología. UBA. 22 a 25 de agosto. 2017 a.

DUCROT, Oswald. El decir y lo dicho. Buenos Aires: Paidós, 1986.

GOLD, Tomás. Cacerolazos y legitimidad política en la Argentina reciente. Del '13-S' al '8-A"'. In: ANNUNZIATA, R. (Comp.). Pensar las elecciones. Democracias, líderes y ciudadanos. Buenos Aires: CLACSO, 2015. p.180-208.

GÓMEZ, Marcelo. Los enmarcados mediáticos en disputa. El caso de la movilización de las clases medias contra el gobierno kirchnerista. IV Encuentro internacional de teoría y práctica política en América Latina, UNMDP, Mar del Plata, 9 a 11 mar. 2016. 
EID\&A - Revista Eletrônica de Estudos Integrados em Discurso e Argumentação, Ilhéus, n. 16 esp. "Discurso e argumentação na política latino-americana, set.2018.

GONZÁLEZ, Mercedes; BORRELLI, Marcelo. Entre víctimas y victimarios: el diario La Nación y la política de derechos humanos de Néstor Kirchner (2003-2007). Revista Electrónica Question, v. 1, n. 23, 2009. Disponível em: http://perio.unlp.edu.ar/ojs/index.php/question/article/view/888. Acesso em: 14 mar. 2017.

HEINICH, Natalie; SCHAEFFER, Jean-Marie. Art creation, fiction. Entre philosophie et sociologie. Nîmes: Éditions Jacqueline Chambon, 2004.

KITZBERGER, Philip. 'La madre de todas las batallas': el kirchnerismo y los medios de comunicación”. In: MALAMUD, A.; De LUCA, M. (Coord.). La política en tiempos de Kirchner, Buenos Aires: Eudeba, 2011. p.179-192.

LACLAU, Ernesto. Discurso. Topos y tropos, n.1, p.1-7, 2004.

. Ideología y posmarxismo. Anales de la educación común. Tercer siglo. año 2, n. 4, p. 20-35, ago.2006.

LACLAU, Ernesto; MOUFFE, Chantal. Hegemonía y estrategia socialista. Buenos Aires: FCE, 2004 [1985].

LATOUR, Bruno. What if we talked politics a Little? Contemporary political theory, $\mathrm{n}$. 2, p.143-164, 2003.

LEFORT, Claude. La cuestión de la democracia. In: La incertidumbre democrática. Barcelona: Anthropos, 2004 [1986].

MARCHART, Oliver. El pensamiento político posfundacional. La diferencia política en Nancy, Badiou, Lefort y Laclau. Buenos Aires: FCE, 2009.

MONTERO, Ana Soledad. ;Y al final un día volvimos! Los usos de la memoria en el discurso kirchnerista (2003-2007). Buenos Aires: Prometeo, 2012.

PLANTIN, Christian. La argumentación. Buenos Aires: Biblos, 2012.

REANO, Ariana. La estructuración simbólica de la democracia argentina en la transición. Prácticas de Oficio: Investigación y reflexión en Ciencias Sociales, n. 7-8, 2011.

RETAMOZO, Martín; SCHUTTENBERG, Mauricio. La política, los partidos y las elecciones en Argentina 2015: ¿Hacia un cambio en el campo político?”. Análisis Político, v. 29, n. 86, p. 113-140, 2016. Disponível em: http://www.memoria.fahce.unlp.edu.ar/art_revistas/pr.7371/pr.7371.pdf. Acesso em: 27 mar. 2017.

ROSANVALLON, Pierre. Por una historia conceptual de lo político. Buenos Aires: FCE, 2003.

VAN DIJK, Teun. Semántica del discurso e ideología. Trad. Cristina Perales. Discurso y sociedad, v. 2, n. 1, p. 201-261, 2008. 
EID\&A - Revista Eletrônica de Estudos Integrados em Discurso e Argumentação, Ilhéus, n. 16 esp. "Discurso e argumentação na política latino-americana, set.2018.

SCHUTTENBERG, Mauricio; FONTANA, Júlian. La apelación a la historia como instrumento de construcción de una identidad 'liberal conservadora'. El diario La Nación, en la crisis de 2001-2002 y en la confrontación con el Gobierno desde el 'conflicto con el campo' al bicentenario. Cuadernos de H Ideas, v. 4, n.4, dez. 2010.

VASILACHIS DE GIALDINO, Irene. Los fundamentos ontológicos y epistemológicos de la investigación cualitativa. Forum Qualitative Sozialforschung, v. 10, n. 2, 2009. Disponível em: http://www.qualitativeresearch.net/index.php/fqs/article/view/1299/2778. Acesso em: 28 mar. 2017

VERÓN, Eliseo. El análisis del 'Contrato de Lectura', un nuevo método para los estudios de posicionamiento de los soportes de los media. In: . Les Medias: Experiences, recherches actuelles, aplications. París: IREP, 1985.

- La palabra adversativa. In: - El discurso político. Lenguajes y acontecimientos. Buenos Aires: Hachette, 1987. p.11-26.

. La semiosis social. Fragmentos de una teoría de la discursividad. Barcelona: Gedisa, 1993.

- Semiosis de lo ideológico y del Poder. La mediatización. Buenos Aires: Facultad de Filosofía y Letras/UBA, 1995.

. Mediatización de lo político. In: GAUTHIER, G. et al. (Comp.). Comunicación y política. Barcelona: Gedisa, 1998. p.220-236.

- Cuando leer es hacer: la enunciación en la prensa gráfica. In: Fragmentos de un tejido. Barcelona: Gedisa, 2004 [1984]. p. 171-192.

VINCENT, Lucía. 'En la Argentina llegó la hora de hablar con la verdad': el diario La Nación como contradestinatario en las elecciones de 2005. XI Congreso Nacional de Ciencia Política. (SAAP-UNER). Paraná, 17 a 20 jul, 2013.

. Los medios y los fines. El gobierno de Néstor Kirchner y su relación con la prensa. Tese (Doutorado em Ciências Políticas). Universidad Nacional de San Martín, 2014.

VOLOSHINOV, Valentin. El signo ideológico y la filosofía del lenguaje. Buenos Aires: Nueva Visión, 1976.

VOMMARO, Gabriel. 'Unir a los argentinos': el proyecto de 'país normal' de la nueva centroderecha en Argentina. Nueva sociedad, n. 261, 2016. Disponível em: http://nuso.org/articulo/unir-los-argentinos/. Acesso em: 28 mar. 2017.

ZEMELMAN, Hugo. Sujeto y subjetividad: la problemática de las alternativas como construcción posible, Polis, v. 9, n. 27, p.355-366, 2010. 
EID\&A - Revista Eletrônica de Estudos Integrados em Discurso e Argumentação, Ilhéus, n. 16 esp. "Discurso e argumentação na política latino-americana, set.2018.

Tradução:

Karina Magno Brazorotto de Sá

Professora de Língua Portuguesa e Espanhola do Instituto Federal de Educação, Ciência e Tecnologia de São Paulo (IFSP).

Israel de Sá

Professor Doutor da Universidade Federal de Uberlândia (UFU).

Forma de citação sugerida:

De DIEGO, Julia. O futuro chegou há pouco tempo. Disputas pela ordem democrática entre o discurso presidencial e a imprensa escrita no âmbito dos panelaços de $2012 \mathrm{e}$ 2013. Trad. Karina Magno Brazorotto de Sá e Israel de Sá. EID\&A - Revista Eletrônica de Estudos Integrados em Discurso e Argumentação, Ilhéus, n. 16 esp. "Discurso e argumentação na política latino-americana”, p. 152-181, set.2018.

Recebido em: 25/07/2018

Aprovado em: 26/08/2018 